\title{
Surgical Release of Trigger Thumb in Pediatrics
}

Mohamed S. Abdelhafiz, Amro A. Fouaad, Mostafa M. Abdelatif*

Department of Orthopedic Surgery, Faculty of Medicine, Al-Azhar University

*Corresponding author: Mostafa M. Abdelatif; Mobile: 01004781515; Email: hmeedmostafa@gmail.com

\begin{abstract}
Background: trigger thumbs in children predominantly present with flexion deformity and a nodule at the MCP joint. Surgical release with a transverse incision and splitting of the A1 pulley achieves good cosmoses and attains a satisfactory range of motion with minimal complications.

Aim of the Work: to analyze the results of treatment of congenital trigger thumb by open surgical release.

Patients and Methods: this study was carried out on 12 patients with congenital trigger thumb treated by surgical release of A1 pulley after obtaining the hospital's Research Ethics Committee approval and written informed consents from the patients.

Results: twelve patients were followed up for a mean of 10 (range 4-16) weeks, by which time they were all free of pain and had normal strength subjectively. Of the 12 patients evaluated postoperatively, all were able to fully extend the interphalangeal joint of the involved thumb. Conclusion: Surgical management is the most common treatment, and this is done effectively and safely in the hands of experienced surgeons with pediatric anesthesiologists.
\end{abstract}

Keywords: trigger thumb, surgical release, children.

\section{INTRODUCTION}

Trigger finger is relatively a common problem among hand disorders. The primary pathology is the discordance between the diameter of the flexor tendons of the finger and the fibro-osseous canals in which those tendons lie, which will lead to limitation of the tendon function necessary for hand movement. When the finger is flexed, catching or locking occurs. Left untreated, this may cause flexion contracture of the proximal interphalangeal joints ${ }^{(1)}$.

Trigger thumb of childhood is known as a pathology of the flexor tendon system. The pathology presenting in childhood is referred to as a congenital entity by numerous authors. While the thumb seems normal, the interphalangeal (IP) joint is held in fixedflexion. A nodule at the base of the metacarpophalangeal (MCP) joint, known as Notta's node, can be palpated. The incidence is reported as less than $0.3 \%$ in childhood ${ }^{(\mathbf{1})}$.

Etiology is not clear. The pathology can be detected soon after birth or in childhood. Bilateral involvement is reportedbetween $25 \%$ to $50 \%$. Treatment can be either conservative or surgical ${ }^{(2)}$.

The incidence of trigger thumb in children is 13:3000. It is ten times more common than trigger finger. The "Notta nodule", first described by Notta ${ }^{(2)}$ in 1850 , can be present on the volar aspect of the metacarpophalangeal joint.

Triggering, snapping, or pain is not common during childhood. Fixed-flexion deformities and Notta nodules are reported as the most frequent symptoms in pediatric cases. Therefore, various reports have stated that fixed-flexion deformity is a rule for trigger thumb in childhood ${ }^{(3)}$.

The diagnosis of congenital trigger thumb in a newborn infant may be delayed because of the characteristics of flexion attitude of thumb. This flexion posturing is normal until the age of 3 months when the child begins to hold the thumb out of the palm. The frequent omission of routine thumb examination in the neonates may delay the detection of this deformity ${ }^{(4)}$.

The differential diagnosis of congenital trigger thumb in childhood may include congenital clasped thumb, spastic thumb in palm, arthrogryposis, and other clutched thumb abnormalities ${ }^{(5)}$.

Despite its frequent occurrence, there still remains controversy over the optimal method of treatment (4). Most authors recommend open or percutaneous surgery to release the A1 pulley ${ }^{(5)}$. Trigger thumb release is quick, relatively easy to perform, and reliable ${ }^{(6)}$.

There are various conservative and surgical methods for the treatment of trigger finger. Steroid and local anesthetic injection, and splint application are recommended in the acute stage.

In case of failure of the conservative approach, or in chronic cases, surgical intervention is required. Nonetheless, percutaneous surgery is currently being used as an alternative method, currently being used as an alternative method. This study aims to evaluate the advantages of open surgery for trigger finger in pediatric cases ${ }^{(7)}$.

\section{AIM OF THE WORK}

Aim of the work is to analyse the results of treatment of congenital trigger thumb by open surgical release. 


\section{PATIENTS AND METHODS}

- After obtaining the hospital's Research Ethics Committee approval and written informed consents from the parents of study patients.

- Patients with congenital trigger thumb were treated by surgical release of A1 pulley.

- All patients were screened for suitability by detailed clinical assessment of their history and physical examination as well as radiological investigations and those who were met the operative criteria were included in this study.

- A grading system was suggested in this study for evaluation of congenital trigger thumb deformity depending on clinical measures:

1- The correction of thumb deformity.

2- The presence or absence of pain.

3- The tolerability of thumb splint.

4- The patient (or parent) satisfaction.

5- The incidence of recurrence.

Inclusion criteria:

1. Age 1-10 years.

2. Duration of follow-up of 3 months or more.

3. Patients fit for surgery.

4. Triggering in the thumb.

\section{Exclusion criteria:}

1. Age less than 1 year.

2. Age more than 10 years.

3. Not associated with other congenital anomalies.

4. Patients done by percutaneous surgical technique.

5. Triggering in fingers other than thumb.

Surgical techniques:

- The surgical procedure was performed with tourniquet control under general anesthesia.

- After skin sterilization and draping, a transverse incision was made at the flexion crease of the thumb MP joint; the Notta's node was usually near this area.

- The ulnar and radial digital nerves were protected. The annular ligament was longitudinally incised and the IP joint of the thumb was then passively extended in order to ensure an adequate release.

- If full correction of the deformity was not achieved, then an oblique pulley partial release was undertaken until the IP joint was in a fully extended position. No nodule excision was performed.

- An extensor-type splint was used for immobilization at nighttime in two cases for 15 days, but other patients did not use the splint.

- Active and passive exercise was started at 1 week after surgery.

- Hand function and parent/patient satisfaction were evaluated at follow-up. No gradation was used for rating, only a report of satisfied or unsatisfied.

- Hand function assessment was based on any reported difficulty of hand use. The recurrence of flexion deformity and thumb IP range of motion were recorded.

- The superficial displacement of the tendon and overlying skin was observed to be bowstringing.

\section{Statistical analysis}

Recorded data were analyzed using the statistical package for social sciences, version 20.0 (SPSS Inc., Chicago, Illinois, USA). Quantitative data were expressed as mean \pm standard deviation (SD). Qualitative data were expressed as frequency and percentage.

\section{RESULTS}

Pre-operatively, interphalangeal joint flexion, key pinch and tip pinch strengths were significantly diminished by the condition compared to the contralateral thumb (Table 1). Section of the A1 pulley effectively corrected these deficits of the thumb and there was no statistical difference between postoperative values and values for the contralateral side (Table 1). Although both key pinch and tip pinch strengths increasedpostoperatively, only tip pinch strength did so significantly (Table 1).

The width of the thumb increased significantly from pre-operative to final follow-up due to the bowstringing of the flexor pollicislongus. This increase was not enough, however, to show a difference with respect to the contralateral side (Table 1). This might suggest that the flexor pollicislongus was flattened against the first metacarpal by the thicker pulley before surgery.

Table (1): Pre-operative, postoperative and contralateral data ${ }^{(8)}$

\begin{tabular}{|l|c|c|c||}
\hline & \multicolumn{2}{|c|}{ Affected Thumb } & Contralat. Thumb \\
\hline \hline & Preop & Postop & $66.8(2.3)$ \\
\hline IP flexion (degrees) & $50.1(3.6)$ & $64.5(2.5)$ & $53.4(2.0)$ \\
\hline MCP flexion (degrees) & $52.9(1.9)$ & $53.9(1.5)$ & $9.7(1.0)$ \\
\hline Tip pinch strength $(\mathrm{kg})$ & $3.9(0.7)$ & $9.5(0.9)$ & $7.5(0.9)$ \\
\hline Key pinch strength $(\mathrm{kg})$ & $5.8(0.8)$ & $6.4(0.8)$ & $20.0(0.4)$ \\
\hline Width of the thumb(mm) & $19.1(0.5)$ & $20.8(0.3)$ & \\
\hline
\end{tabular}


Table (2): Data of 12 patients

\begin{tabular}{|l|c|c|c|c|c|c||}
\hline Patient & $\begin{array}{c}\text { Affected } \\
\text { side }\end{array}$ & $\begin{array}{c}\text { Age of } \\
\text { onset }\end{array}$ & $\begin{array}{c}\text { Age at } \\
\text { surgery }\end{array}$ & $\begin{array}{c}\text { Post operative } \\
\text { splint }\end{array}$ & $\begin{array}{c}\text { Recurrent } \\
\text { Triggering }\end{array}$ & Follow up \\
\hline \hline $\mathbf{1}$ & $\mathrm{Rt}$ & 12 & 22 & - & - & 3 \\
\hline $\mathbf{2}$ & $\mathrm{Rt}$ & Birth & 36 & - & - & 3 \\
\hline $\mathbf{3}$ & $\mathrm{Rt}$ & 16 & 34 & - & - & 3 \\
\hline $\mathbf{4}$ & $\mathrm{Lt}$ & 18 & 56 & - & - & 6 \\
\hline $\mathbf{5}$ & $\mathrm{Rt}$ & Birth & 84 & - & - & 4 \\
\hline $\mathbf{6}$ & $\mathrm{Rt}$ & 2 & 78 & + & - & 3 \\
\hline $\mathbf{7}$ & $\mathrm{Lt}$ & Birth & 54 & - & - & 3 \\
\hline $\mathbf{8}$ & $\mathrm{Rt}$ & Birth & 48 & - & - & 6 \\
\hline $\mathbf{9}$ & $\mathrm{Rt}$ & 6 & 60 & - & - & 6 \\
\hline $\mathbf{1 0}$ & $\mathrm{Lt}$ & 9 & 60 & + & - & 5 \\
\hline $\mathbf{1 1}$ & $\mathrm{Lt}$ & 6 & 24 & - & - & 4 \\
\hline $\mathbf{1 2}$ & $\mathrm{Rt}$ & 9 & 33 & - & - & 6 \\
\hline
\end{tabular}

\section{Comparison between age of onset and age of surgery}

There were 12 trigger thumbs in 12 patients; trigger thumb was the only abnormality of the hand, without any other underlying disease. In all, 4 were boys and 8 were girls. The mean age was 9 months (range: birth-18 months) at onset and 53 months (range: 22-84 months) at surgery.

There were four cases of trigger thumb noted at birth. In ten thumbs, the condition was noted in the first year of life. The predominantly affected side was the right.

Two thumbs were immobilized at nighttime with a postoperative splint for 15 days.

Surgical treatment was performed between 22 months to 84 months of age.

The mean follow-up period was 3 months. No wound infection, neurovascular injury, excessive pain, or thickening of scar was observed in any patient.

Bowstringing and MP joint hyperextension were not found. As compared to the normal side, the operated thumbs had full, active IP joint extension. Satisfaction regarding the procedure was reported by both patients and parents. Indeed, both groups reported the normal function of both hands. All patients reported solution of Notta's node. However, one patient reported asymmetrical thumb size.

\section{An Example of Cases History}

Female patient 3 years old was brought by her parents to outpatient clinic with complaint of deformed RT thumb, the deformity was noticed by her mother at the age of five months and on visiting a clinic she was told by a general practitioner that the deformity would settle down with the child growth.
The deformity did not produce pain nor interfere with routine daily activities e.g. playing or self feeding.

Their past medical, birth, family and social histories were unremarkable. The mother denied any history of drug intake during pregnancy.

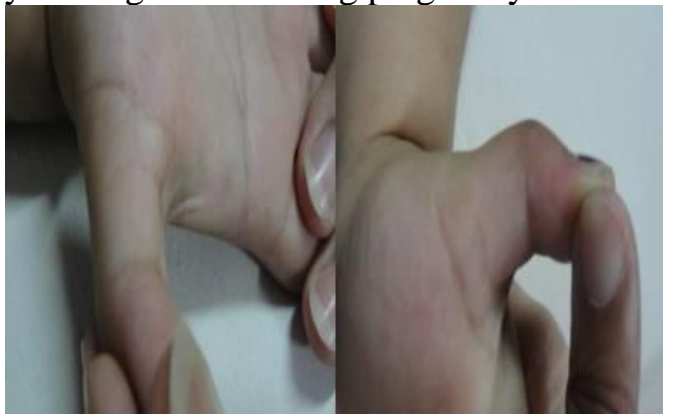

Figure (1): 3 years old female with a trigger thumb Examination

On examination, the hand examination was unremarkable except for the flexion contractures of the IP joints of the thumbs making active or passive IP extension impossible.

A non-tender hard nodule was present at the IP joints along with thickening of flexor pollicislongus (FPL) tendon. The triggering was absent. Distal sensations and capillary refill were normal bilaterally. No other apparent physical abnormality was found.

Based on history and examination, a diagnosis of congenital PTT was made.

\section{Surgical treatment}

Surgical release of A1 pulley of FPL tendon was done. Surgery was performed at the age of three years. 


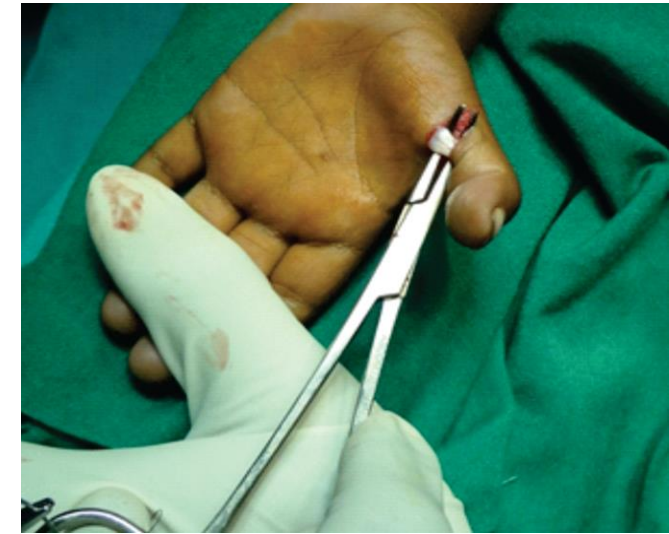

Figure (2): Intraoperative release of the tendon

\section{Postoperative}

Postoperatively, the patients' thumb was protected with thumb-spica splints for five days and an extensive occupational therapy program was started to improve active extension and motor skills.

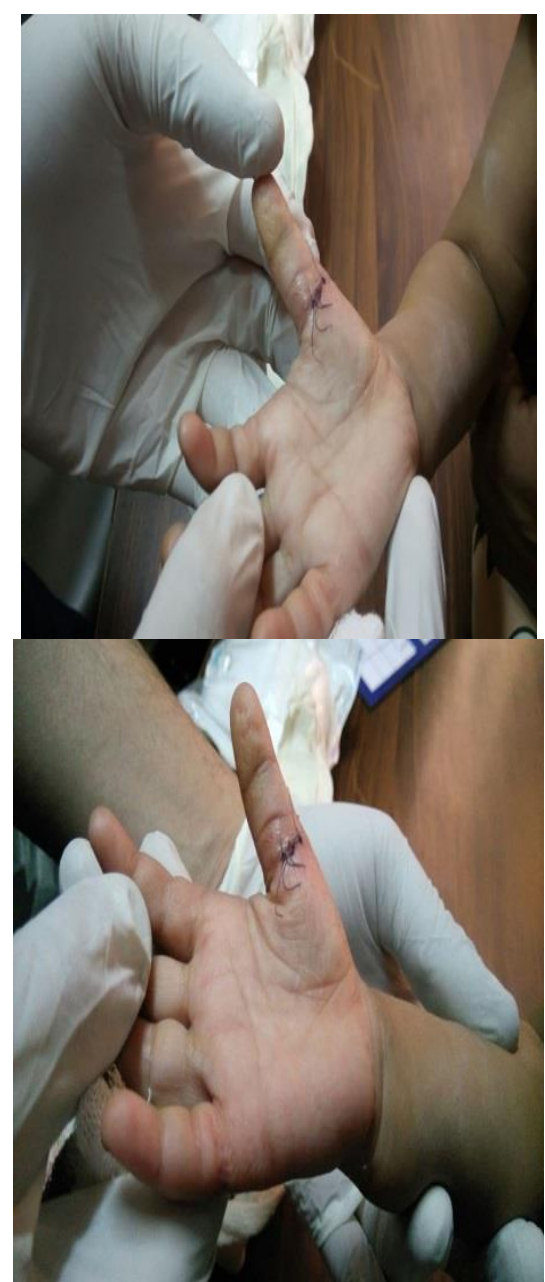

Figure (3): 1 week postoperative
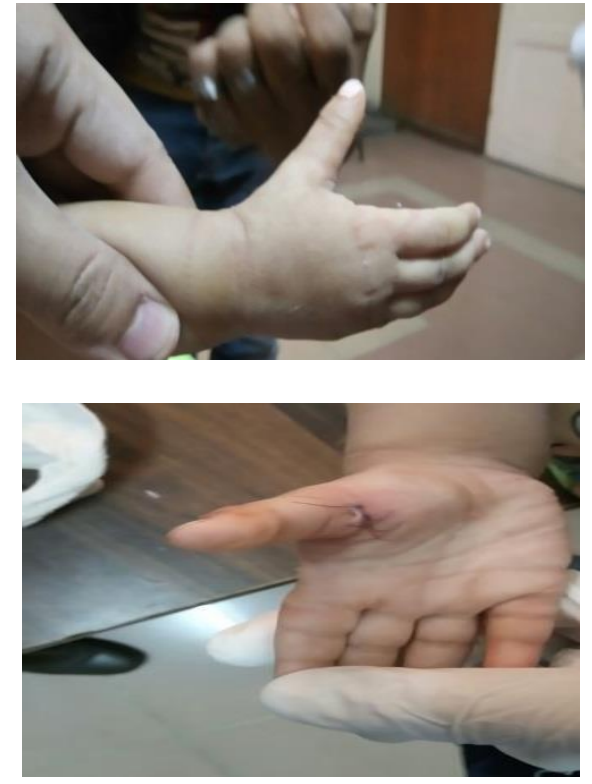

Figure (4): 2 weeks post- operative

\section{Follow up after three months:}

On follow-up after three months, the patients had full active extension of the IP joints and no sensory deficit in their thumbs

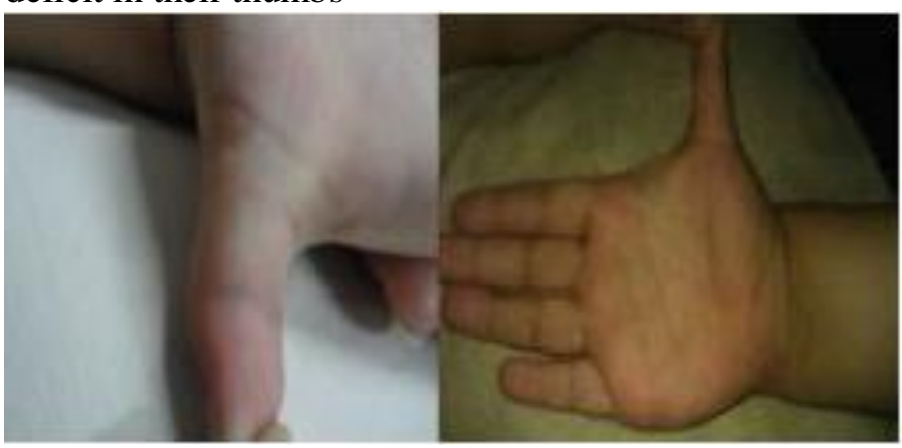

Figure (5): After 3 months

\section{DISCUSSION}

Etiology, pathology and even treatment are some what controversial in trigger thumb of childhood. Some authors have mentioned the relation of genetic inheritance in congenital trigger thumb by additional anomalies, positivefamily history and multiplicity of the pathology in twins ${ }^{(\mathbf{1})}$.

Some authors have proposed that the problem mayarise from tendon, sheath or pulley, similar to the pathology in adults1-3. Timing and type of surgery are also controversial ${ }^{(2)}$.

In addition to those who support healing, others advocate conservative treatment such as exercises, splinting and corticosteroid injection. Unsuccessful conservative treatment and age over three years are the most absolute indications for surgical treatment ${ }^{(9)}$.

If there exists restriction in IP extension, or rigidity and thickening in thetendon sheath, some 
authors advocate urgent surgical release. In adults, trigger finger is most often seen in the 5th and 6th decade. It is seen extremely rare in childhood. The incidence in children is estimated to be between $0.05 \%$ and $0.3 \%{ }^{(\mathbf{1 0 )}}$.

Trigger finger is generally seen in the thumbs in children and this has been reported to be 10 times more frequent than other triggering diseases of the fingers ${ }^{(11)}$.

This pathology may be encountered as either congenital or developmental.Congenital trigger thumb is dealt with under the heading of differentiation of hand anomalies together with arthrogriposis, camptodactyly, madelung deformity and clinodactyly ${ }^{(\mathbf{1 2})}$.

In addition, there may be accompanying cardiac, cleft lip and cleft palate pathologies. Although there are cases of congenital pathologies of trigger thumb cases occurring later in life, there is no information related to symptoms in later life ${ }^{(\mathbf{1 3})}$.

The problem in trigger finger is that impairment in the viscosity of the finger flexor system inhibits movement. Generally the problem is located in the metacarpophalangeal joint anteriorly and results in the narrowing of the hard fibrous band of the A1 pulley (12). In the current study, the problem was in the A1 pulley in all the cases.

In the diagnosis, the families stated that the child's fingers were bent and they tried to correct pathology, however they were not successful or managed it with difficulty and the child cried at that time. The importance for the differential diagnosis was to determine whether or not the flexion deformity originated in the joint.

This is understood by the patient showing straightening of the interphalangeal joint when flexion is made from the metacarpophalangeal joint ${ }^{(14)}$.

In this respect another study has reported spontaneous correction of the deformity, although those cases were below 12 months of age and were cases with mild symptoms ${ }^{(15)}$.

In the current study, the youngest case was 22 months old and because families were generally worried about surgical intervention, the children were brought to hospital at a mean 8.5 months after the onset of symptoms and during that time no improvement was reported.

In contrast, reported spontaneous recovery within four years of the great majority of cases followed-up without treatment ${ }^{(\mathbf{1 6})}$.

Treatment choices include the use of splint/plaster, corticosteroid injections, physical therapy and percutaneous or open surgical loosening (17)
The use of a splint may be useful in early stage cases and adults ${ }^{(\mathbf{1 8})}$. Problems of conformity in pediatric patients may result in failure of the treatment. However, in a study where long-arm plaster was applied to three patients aged 20,26 and 32 months, it was reported that symptoms had recovered ${ }^{(\mathbf{1 9})}$.

Although there are studies defining the application of corticosteroid injections as the right approach, it is not as foolproof as indicated. The close proximity of digital blood vessels and surface course may cause partial tissue necrosis as a result of an injection within the digital artery ${ }^{(20)}$.

Physical therapy methods include hot pack application, transcutaneous electrical nerve stimulation (TENS), ultrasound, friction massage and stretching exercises ${ }^{(18)}$.

Anti-inflammatory therapy may be given in addition to prevent inflammation. In two different studies where two cases aged four and five years old received physical therapy and anti-inflammatory therapy, positive results were reported from the treatment $^{(10)}$.

In another study, the mothers of children with trigger thumb were taught passive stretching exercises and after a mean 28 months of application positive results were obtained in the vast majority of cases ${ }^{\mathbf{2 1})}$.

Although there are different treatment methods in use, it has been suggested that particularly in childhood, surgery is required as the first treatment ${ }^{(21)}$.

Surgical treatment is made in the form of a percutaneous or open incision in the longitudinal plane of the A1 pulley system.

Very good results from loosening operations performed on 63 cases aged between 12 and 60 months were reported ${ }^{(22)}$.

Researchers have attempted the percutaneous approach, which has come into widespread use in recent years, because it consists of the loosening of the A1 pulley in the treatment of trigger finger. The percutaneous approach has been presented in literature as an alternative method with emphasis on surgery duration being longer than that of the open technique localisation in respect of scarring in the postoperative period $^{(\mathbf{1 9})}$.

In the current study, as all the cases had involvement of the thumb and because of the risks, open surgery technique was applied.

Other than these two methods, a mini-open technique with an incision of $1 \mathrm{~cm}$ is done and reported that neurovascular structures could be easily visualised as in the open technique and no complications were encountered ${ }^{(23)}$. 


\section{CONCLUSION}

Surgical management is the most common treatment, and this is done effectively and safely in the hands of experienced surgeons with pediatric anesthesiologists. Surgical release of the trigger thumb includes release of the A1 pulley, whereas surgical release of the trigger finger includes release of the A1 and $\mathrm{A} 3$ pulleys with resection of one slip of the FDS tendon, to achieve reliable results.

\section{REFERENCES}

1. Wolfe SW (2005): Tenosynovitis. In: Green DP, Hotchkiss RN, Pederson WC, Wolfe SW, editors. Greens operative hand surgery, $5^{\text {th }}$ ed., vol. 2, Philadelphia: Elsevier Churchill Livingstone.

2. Farr S, Grill F, Ganger R, Girsch W (2014): Open surgery versus nonoperative treatments for paediatric trigger thumb: a systematic review. J Hand Surg Eur., 39:719-26.

3. Shah AS, Bae DS (2012): Management of pediatric trigger thumb and trigger finger. J Am Acad Orthop Surg., 20:20613.

4. Ogino T. Trigger thumb in children: current recommendations for treatment. J Hand Surg Am. , 33:982-4.

5. Han SH, Yoon HK, Shin DE et al. (2010): Trigger thumb in children: results of surgical treatment in children above 5 years of age. J Pediatr Orthop., 30: 710-4.

6. Wang H, Wang P, Amajoyi O, Chen CJ, Chen GY (2017): The Safety of Percutaneous Trigger Digit Release Increased by Neurovascular Displacement with Local Hydraulic Dilatation: An Anatomical and Clinical Study. Medical science monitor: international medical journal of experimental and clinical research, 23:5034.

7. Tarbhai K, Hannah S, von Schroeder HP (2012): Trigger finger treatment: A comparison of 2 splint designs. J Hand Surg Am., 37:243-9.

8- Boretto J, Alfie V, Donndorff A, Gallucci G, De Carli P (2008): A prospective clinical study of the A1 pulley in trigger thumbs. Journal of Hand Surgery, 33(3):260-5.

9. Kelle B (2012): Trigger finger in childhood: A case report. J. P.M.R. Sci,. 15: 61-63.
10. Pargali N, Habibzadeh $F$ (2011): Bilateral trigger finger in a 5-year-old child: Case report. J. Plast. Reconstr. Aesthet. Surg., 64: 283-284.

11. Medina J, Lorea P, Marcos A, Martin F, Reboso L, Foucher G (2008): Flexion deformities of the thumb: Clasped thumb and trigger thumb. Chir Main., 27:3539.

12. Ty JM, James MA (2009): Failure of differentiation: Part II. Hand.Clin., 25: 195-213.

13. Yenidünya MO (2010): Trigger thumb: as a congenital, developmental and young health problem. New Medical Journal, 27: 33-36.

14. Wolfe SW (2005): Tenosynovitis. In: Green, D.P., Hotchkiss, R.N., Pederson, W.C., Wolfe, S.W., Green's operative hand surgery. Vol. 2, $5^{\text {th }}$ ed. Philadelphia: Elsevier Churchill Livingstone, pp. 21372158.

15. Moon WN, Suh SW, Kim IC (2001): Trigger digits in children. J. Hand. Surg. Brith., 26: 11-12.

16. Baek GH, Lee HJ (2011): The natural history of pediatric trigger thumb: A study with a minimum of 5 years follow-up. Clin.Orthop. Surg., 3: 157-160.

17. Patel MR, Bassini L (1992): Trigger fingers and thumb: When to splint, inject or operate. J. Hand. Surg. Am., 17: 110-113.

18. Colbourn, J, Heath, N, Manary, S, Pacifico, D (2008): Effectiveness of splinting for the treatment of trigger finger. J. Hand. Ther Am., 21: 336- 343.

19. SaeedBanadaky SH, Baghianimoghadam B (2012): Long arm casting for treatment of trigger finger in children: Report of three cases. J. Med. Life, 5: 105106.

20. Park J, Dumanian GA (2009): Shower emboli and digital necrosis after a single corticosteroid injection for trigger thumb: Case report. J. Hand. Surg. Am., 34: 313-316.

21. Sevencan A, Inan U, Kose N, Omeroglu H, Seber S (2010): Percutaneous release for trigger thumbs in children: Improvements of the technique and results of 31 thumbs. J Pediatr Orthop., 30: 705-709.

22. Amradi A, Dardane MA (2011): Percutaneous release of trigger thumb in children: 63 cases. Chir.Main., 30: 102-104.

23. Ertürk C, Altay MA, Kalender AM (2009): Miniaçıtetikparmakgevşetmesi. Tıp Araştırmaları Dergisi., 7: 141-144. 